\title{
Pluralismo metodológico e transdisciplinaridade na complexidade: uma reflexão para a administração*
}

\author{
Onésimo de Oliveira Cardoso** \\ Francisco Antonio Serralvo***
}

SumÁrio: 1. Introdução; 2. Pluralismo metodológico na transdisciplinaridade; 3. A abordagem da complexidade e os caminhos da pluralidade; 4. Pluralismo e complexidade na administração; 5. Considerações finais.

SumMARY: 1. Introduction; 2. Methodological pluralism in transdisciplinarity; 3. Approach to complexity and paths of plurality; 4. Pluralism and complexity in management; 5. Final remarks.

Palavras-chave: transdisciplinaridade; estudo da administração; complexidade.

KEY WORDs: transdisciplinarity; management study; complexity.

Uma visão transdisciplinar da área significa buscar novas posturas epistemológicas e metodológicas que não sejam apenas justaposição de ideias e métodos, mas sim uma tentativa na busca de insights e abordagens múltiplas que possam dar conta da essência dos fenômenos da área, que de alguma maneira estão conectados com o universo amplo das ciências sociais nos seus diferentes domínios e corpo multidisciplinar. Este artigo busca, no enfoque da complexidade, fundamentação para o desenvolvimento de um pluralismo metodológico sustentado pela transdisciplinaridade, e desenvolve um questionamento às racionalidades dominantes, que, de alguma maneira, têm servido de referências teóricas e epistemológicas para justificativa de uma administração onde não há espaço para emancipação e criatividade. O artigo desenvolve novas perspectivas epistemológicas que podem significar análises mais

\footnotetext{
* Artigo recebido em mar. e aceito em out. 2008.

** Doutor em comunicação. Professor associado da Pontifícia Universidade Católica de São Paulo (PUC-SP), editor da revista Administração em Diálogo. Endereço: Rua Monte Alegre, 984, sala 4E-04 — CEP 05014-901, São Paulo, SP, Brasil. E-mail: o-cardoso@uol.com.br.

*** Pós-doutor em administração e doutor em ciências sociais. Professor titular da Pontifícia Universidade Católica de São Paulo (PUC-SP), vice-coordenador do Programa de Estudos PósGraduados em Administração. Endereço: Rua Monte Alegre, 984, sala 4E-04 — CEP 05014-901, São Paulo, SP, Brasil. E-mail: serralvo@pucsp.br.
} 
adequadas e fecundas dos fenômenos individuais e coletivos que caracterizam o universo das organizações, nos seus conflitos, nas suas contradições e na sua própria razão de ser e na da sociedade.

Methodological pluralism and transdisciplinarity in the complexity: a reflection on management

A transdisciplinary view of the management area means looking for new epistemological and methodological stands that are not only an overlap of ideas and methods, but an attempt in the search of insights and multiple approaches that can embrace the essence of the phenomena of the area. To some extent, they are connected with the wide universe of social sciences in its different domains and multidisciplinary body. This article focuses on complexity, in search of foundations for the development of a methodological pluralism supported by transdisciplinarity. It also questions the mainstream rationalities that, to some extent, have served as theoretical and epistemological framework to a management where there is no room for emancipation and creativity. The article develops new epistemological perspectives that may mean more adequate and fertile analyses of the individual and collective phenomena. They characterize the organizations' universe, in their conflicts, contradictions and own reason of being and that of the society.

\section{1 . Introdução}

Este artigo reflete sobre os limites das abordagens teóricas e metodológicas do campo da administração, e questiona o apego à disciplinaridade institucionalizada e a busca sempre constante de procedimentos metodológicos unívocos, com fortes apelos quantitativos, deterministas e mecanicistas, que se inspiram na velha sempre atual abordagem positivista e funcionalista. $\mathrm{O}$ texto tenta recuperar e corroborar pela legitimação da abordagem da complexidade, com destaque para teóricos como Morin, Genelot e Le Moigne, como campo de desenvolvimento de uma transdisciplinaridade, que avança sobre os apegos disciplinares e que fortalece um pluralismo metodológico, como uma instância possível da produção de um conhecimento possível sobre a realidade, sem a pretensão de respostas definitivas e cabais sobre os objetos da administração.

Será feita uma análise teórico-crítica, livre de formalismos, pois a esfera metodológica não é um campo sagrado que produz verdades inquestionáveis, mas que torna possível o máximo que se pode alcançar, a construção de pensamentos mais verdadeiros, que deem conta da multiplicidade de arranjos discursivos, de efeitos de sentido e de dimensões metafóricas que proliferam nas discussões acadêmicas. É um exercício hermenêutico, que permite uma 
interpretação que procura os conceitos além do texto, as significações além da palavra, conforme salienta Santos (1991), sem contudo, deixar de entender que o texto tem seus limites, pois “...as palavras, especialmente em torno de conceitualizações, servem para aprisionar, imobilizar e ferir aquilo a que elas buscam se referir" (Burrel, 1999:444). Toda a elaboração de um texto exige um exercício crítico de construção, reconstrução e transgressão. Uma espécie de transgressão epistemológica contra toda a sorte de formalismos e modelos que legitimam situações de domínio, opressão e que impedem a busca da criatividade e da realização pessoal e coletiva. Assim, entende-se a prática de análise e interpretação como uma aventura sem limites na busca de argumentos mais fortes, sem temor do impreciso, confuso e complexo.

Este artigo ainda traz a reflexão teórica da complexidade para o universo da administração, destacando o papel das organizações complexas quanto a sua existência e intencionalidades com destaque para o desempenho de gestores no desenvolvimento estratégico de uma organização.

Entende-se que o campo da administração se insere primordialmente no âmbito das ciências sociais, que é na sua essência transdisciplinar e de metodologias múltiplas, apesar de se reconhecer o enquadramento que as ciências naturais sempre exerceram sobre a área, impondo seus modelos unívocos de análise e interpretação.

A visão de campo disciplinar entendida aqui está muito próxima daquilo que Bourdieu (1997:57) expressou:

Um campo é um espaço estruturado, um campo de forças — há dominantes e dominados, há relações constantes, permanentes, de desigualdade, que se exercem no interior desse espaço - que é também um campo de lutas para transformar ou conservar esse campo de forças. Cada um, no interior desse universo, empenha em sua concorrência com os outros a força (relativa) que detém e que define sua posição no campo e, em consequência, suas estratégias.

Entende-se, assim, o campo da administração como "um campo de lutas para transformar", ainda que a maioria dos estudiosos e pesquisadores tenham procurado legitimar a uniformidade, o modelo de análise e o que é positivo, eliminando o confronto, as contradições, a ausência, a mudança e principalmente a crítica.

Todavia, essa estratégia de "conservação do campo" não tem se desenvolvido de maneira tranquila e nem alcançado resultados positivos, quanto à qualidade, pertinência e a relevância daquilo que se tem produzido como "conhecimento científico" na área. 
Mattos (2000) chegou a afirmar com certa ênfase que “...não é difícil sustentar que a teoria administrativa corrente no mercado, não vai, pelo seu método, muito além do senso comum bem informado e com boa retórica". Ainda que se reconheça o valor antropológico do senso comum e apesar da grande utilidade que apresenta na solução dos problemas diários, ligados à sobrevivência humana, o senso comum não deixa de ser um conhecimento impreciso e fragmentado. Limitado às condições subjetivas, com baixo poder de crítica e, por isso, com tendências dogmáticas e mantendo o ser humano como expectador demasiadamente passivo da realidade.

Reforçando o argumento de Mattos, constata-se que na produção acadêmica da área existe o domínio do método de estudos de caso, com dados de evidência, nos quais se destacam as referências documentais e descrições "neutras" dos dados obtidos e conteúdos de entrevistas feitas com dirigentes das organizações estudadas, trazendo as obviedades do senso comum (se funcionou no passado, funciona hoje e vai funcionar no futuro), em que existe total ausência de análise e interpretação. Esses estudos se tornam mais adequados ao ambiente profissional do que na esfera acadêmica. Portanto, a afirmação de Mattos (2000), mesmo passível de crítica, não deixa de ser um incômodo perturbador para os que produzem conhecimento na área e que desejam enfrentar os desafios que o mundo globalizado apresenta com seus aspectos de desordem e complexidade.

O grande desafio para a área da administração é reconhecer que a maioria de seus objetos de estudos está relacionada com outras áreas do conhecimento. Daí a necessidade de se produzir um encontro, com profundidade e competência, com insights e abordagens pertencentes a metodologias múltiplas e fundamentos teóricos multidisciplinares. Não é difícil deixar de reconhecer que as fronteiras da área da administração carregam, pela configuração de seus objetos voláteis, mutáveis e de aspectos obscuros, a difícil e quase impossível tarefa de circunscrever seus objetos nos modelos rígidos de análises, num saber positivo enraizado e legitimado, e no prestígio institucional acumulado.

O conhecimento na área da administração exige pensar e repensar uma nova maneira de se compreender e entender as mudanças do próprio saber e das suas dimensões plurais, quer sejam do ponto de vista teórico-epistemológico, quer sejam dos procedimentos metodológicos, que estão em pauta nos dias atuais.

O campo de estudo tem lidado com alguns conceitos e aportes teóricos que de alguma maneira tornaram-se obsoletos. Outros perderam sua relevância e existem os que precisam ser recriados e repensados. Vive-se e trafega-se 
hoje no espaço da contaminação do sentido, da colisão das interpretações, em confronto com abordagens teóricas e procedimentos metodológicos defasados e infrutíferos para se entender o novo e "transformar" o "campo disciplinar".

Perdeu-se de tal maneira o sentido da transdisciplinaridade e dos procedimentos plurais na produção científica e no fazer pedagógico, que as afirmações "isso não é da minha área" e "esse não é do meu campo" tornaram-se um mote aceitável e tolerável nas lides acadêmicas. De alguma maneira, muitos se perderam nos vícios das metáforas "área" e "campo", como se fosse possível ser um bom teórico de administração entendendo somente de administração.

Presos, portanto, aos formalismos metodológicos e a uma visão estreita e limitada dos objetos, torna-se imperativo discutir e avaliar a importância de uma prática mais aberta e pluralista de análise e interpretação.

\section{Pluralismo metodológico na transdisciplinaridade}

Pensar a administração hoje significa resgatar a totalidade dos processos organizacionais e repensar a prática da pesquisa na área. Muitos trabalhos, no Brasil, realizados nos eventos da administração, principalmente no Enanpad, expressam um pluralismo disciplinar, isto é, análises feitas com a colaboração de aportes teóricos de diferentes disciplinas, como psicologia, comunicação, economia, sociologia, antropologia e outras, no sentido de se conhecer um objeto comum. Todavia, ao invés da construção de um pensamento integrado, o que acaba acontecendo é que dentro de cada ótica particular há apenas uma justaposição de conhecimentos díspares e até mesmo confronto de ideias e métodos.

Não significa que a justaposição e a acumulação disciplinar do conhecimento sejam proibidas, mas o que se entende por transdisciplinaridade é algo "...que se define sobretudo pela exigência da retomada reflexiva das experiências humanas e de seus resultantes em multidimensionalidade" (Chanlat, 2000:64). Isso, portanto, não se realiza apenas com justaposição de aportes teóricos e nem com soma de procedimentos metodológicos, mas com concepções inovadoras sobre o mundo, sobre o sentido da existência do ser humano e da sociedade e consequentemente com novas formas de conhecimento e da maneira de se compreender a realidade.

A saída para o impasse da justaposição de ideias e procedimentos significa a busca de outra forma de abordagem, senão vai se ficar estabelecendo ligações contínuas entre áreas com o mesmo interesse, voltando a passar pelos mesmos pontos, e criando um ciclo vicioso que terá sempre como resultado 
"o argumento fraco". Daí a necessidade de se buscar um novo processo de entendimento.

É nesse sentido que se procura reforçar a legitimidade da complexidade, que valoriza o pluralismo, a transdisciplinaridade e a superação de toda a sorte de reducionismo de uma maneira nova não só de se olhar o mundo, mas tendo em vista sua transformação, por isso exige um grande esforço de transformação de comportamentos consagrados de estudo e de pesquisa.

Para o desenvolvimento da área da administração, como um campo de estudo, em meio a conflitos e contradições, é necessário possuir uma visão transdisciplinar, como elemento complementar à aproximação disciplinar, superando os formalismos excessivos, a rigidez das definições e o culto à objetividade. Uma transdisciplinaridade que não significa apenas uma simples mudança de nomenclatura, mas sim um intercâmbio de enfoques epistemológicos, métodos e visão de mundo. Essa postura significa trabalhar conceitos e teorias comuns às distintas disciplinas das ciências sociais, o que significa mais do que simples compartilhar de ideias e metodologias. Para construção do saber não existe um procedimento metodológico unívoco, uma espécie de cânone sagrado, como sempre defenderam os positivistas obnubilados pela inspiração empirista.

Contrário a essa ideia da univocidade quanto ao método, Feyerabend (2005:214) afirma que "não há visão científica do mundo, assim como não há ciência uniforme - exceto nas mentes dos metafísicos, professores e cientistas cegos pelas realizações do seu campo especial". Pode-se até questionar a radicalidade do autor, mas não se pode negar a pertinência da afirmação.

Se não existe uma "visão científica" que possa ser a grande referência do que é e não é ciência, existem as visões que se impõem como tal. Sabe-se que todo o século passado foi dominado pela abordagem positivista e toda sorte de neopositivismos. Essa fase teve seu início em meados do século XIX, em que conhecer significava apenas quantificar e mensurar, e que já no final desse século era duramente criticada por Nietzsche (1976:271), de forma veemente, quando dizia que: "uma interpretação que permite que se conte, que se calcule, que se pese, que se toque, nada mais é despropósito e ingenuidade, admitindo-se que não seja demência e idiotice". Apesar da crítica contundente, a abordagem positivista chega ao século XXI com novas roupagens, mas sempre fiel aos princípios da mensuração.

Essa visão determinista, que privilegia a "geografização" dos objetos, teve impacto significativo na área da administração. Em um estágio inicial, essa racionalidade e a análise de resultados, com base em dados numéricos, acabaram fortalecendo a organização e desvalorizando o ser humano que, nas 
engrenagens da produção industrial, tornou-se uma peça que deveria apresentar a maior eficiência possível, de modo a se encaixar nos estatutos mecânicos e burocráticos da época. O campo da administração, para dar inteligibilidade ao comportamento dos indivíduos na organização, apropria-se de uma vertente do campo da psicologia, o chamado behaviorismo metodológico de Watson (1925), que entendia como um campo puramente objetivo e experimental das ciências naturais e que propunha entender o comportamento humano exclusivamente por meio de comportamento e observações da psicologia animal.

$\mathrm{Na}$ psicologia animal já se pode recorrer à observação do comportamento exterior e de processos fisiológicos, mas não a sensações íntimas, autocompreensão ou depoimentos pessoais. O estudo do comportamento dos animais não precisa pressupor quaisquer processos de consciência dessas criaturas. Todavia, esse ponto de vista, aplicado nos seres vivos inferiores, aplica-se a seres humanos. Mesmo se considerando uma grande evolução, após os anos 1960, as pesquisas no âmbito da etologia animal, quando estudou-se os chimpanzés no seu meio natural e não no cativeiro, a descoberta de fenômenos cognitivos, psicológicos e sociais no mundo dos chimpanzés, ainda é bastante complexa a transferência de experiências do mundo animal para o âmbito do ser humano.

Tudo o que diz respeito à consciência, ao espírito, à imaginação e às ideias faz parte daquelas hipóteses supérfluas, se não insensatas, que não podem ser levadas a sério do ponto de vista científico. Watson (1925) acreditava poder explicar as atitudes humanas em seu discurso, analisando-as apenas na forma em que elas se apresentam ao observador; as experiências íntimas do indivíduo, às quais o observador obviamente não tem acesso, são vistas como ficções, já que supostamente não têm qualquer relação com os processos na vida real.

E o dramático, nessa história, é que apesar de todas as conquistas realizadas, no decorrer do século XX, pelas abordagens gestaltistas, piagetianas, freudianas e até mesmo da psicologia social de Mead (1967) ainda permanece, nas análises e interpretações dos dias atuais, a ideia de um ser humano desprovido de interioridade e de cognitividade. Essa tendência, que ainda perdura nos dias atuais, cumpre assim o papel absurdo de se entender o ser humano e o seu comportamento na mesma dimensão de comportamento dos animais inferiores. Morin (2002:157) comenta que "a racionalização pode, a partir de uma proposição inicial absurda e fantasmagórica, edificar uma construção lógica e dela deduzir todas as consequências práticas". Se essa afirmação não se aplica cabalmente ao behaviorismo metodológico de Watson (1925), tem muito a ver. 
A apropriação dos enfoques positivistas, funcionalistas e behavioristas produziu e ainda produz trabalhos com ênfase na mensuração, na demonstração de nexos da causalidade de forma linear e unívoca, e na replicação, que são as características dos procedimentos metodológicos, quantitativos, que conferem à pesquisa o tão almejado rigor científico ou o alcance do que se denominou "verdade científica". Todavia, não é necessário ser nenhum epistemólogo para entender que na maioria das vezes esse objetivo é uma quimera. Fazendo um contraponto a essa visão de conhecimento científico, Morin (2005:69) afirma: "estamos condenados ao pensamento incerto, a um pensamento trespassado de furos, a um pensamento que não tem nenhum fundamento absoluto de certeza".

Prigogine (1996:14), cuja posição ilustra o que foi dito por Morin (2005), acredita que estamos numa grande aventura, ao entrarmos no século XXI: "assistimos ao surgimento de uma ciência que não mais se limita a situações simplificadas, idealizadas, mas nos põe diante da complexidade do mundo real, uma ciência que permite que se viva a criatividade humana como expressão singular de um traço fundamental comum a todos os níveis da natureza".

A ideia de uma causalidade linear e única: "tal causa produz tais efeitos", apesar da ambiguidade dos discursos existentes, pode até encontrar respaldo em áreas restritas das ciências físico-químicas. Todavia, em ciências humanas e sociais, pode-se afirmar, sem medo de errar, que não existe a unicausalidade, mas fenômenos e acontecimentos multicausais que, por sua vez, produzem efeitos múltiplos. É, portanto, inglória a tentativa de se obter, nas ciências sociais, causas únicas que expliquem um determinado efeito. Além do mais, os objetos de estudo, nas ciências sociais, além de sofrerem a interferência direta do pesquisador, o que não é novidade para os físicos quânticos, engloba os próprios sujeitos pesquisados. Portanto, é fundamental não se cair nas armadilhas do tipo puxa-empurra no âmbito da administração, mas antes, buscar conexões e interconexões. Afinal, todas as partes do universo são solidárias.

Entretanto, a causalidade está presente nas "entranhas" da pesquisa quando se tenta mostrar ou demonstrar que certos dados produziram certos resultados, provando, assim, que tal resultado é a consequência dos dados em questão, isso é uma falácia, pois não se demonstrou que não podem existir outros dados capazes de dar origem ao mesmo resultado. "Se p então q", fórmula citada na maioria dos manuais de metodologia, não dá conta da complexidade que envolve relações causais.

Sem dúvida, essa visão de produção do conhecimento científico, criticada por Nietzsche (1976), entrou numa profunda crise, que se tornou irreversí- 
vel, por não dar conta dos problemas do mundo globalizado e em permanente transformação. Assim, novos olhares, abordagens teóricas e novos enfoques metodológicos se impõem para se conhecer os novos tempos em que as mudanças ocorrem de maneira acelerada. Fato tão bem diagnosticado e caracterizado por Santos (1991:28):

Em vez da eternidade, a história; em vez do determinismo, a imprevisibilidade; em vez do mecanicismo, a interpretação, a espontaneidade e a auto-organização; em vez da reversibilidade, a irreversibilidade e a evolução; em vez da ordem, a desordem; em vez da necessidade, a criatividade e o acidente.

Nesse novo tempo, entende-se a importância da abordagem da complexidade na sua proposta em superar as interpretações reducionistas, simplificadoras e fragmentadas da realidade e estabelecer um novo olhar para uma realidade em que "os objetos têm fronteiras cada vez menos definidas; são constituídos por anéis que se entrecruzam em teias complexas com os dos objetos restantes, a tal ponto que os objetos em si são menos reais que as relações entre eles" (Santos, 1991:33-34).

A abordagem da complexidade nos impõe uma visão de totalidade da realidade que nenhum procedimento de ordem quantitativa poderá dar conta. Einstein (1971, citado por Feyerabend, 2005:202) já se posicionava quanto à tendência da ditadura da mensuração, perguntando: "não é realmente estranho que os seres humanos sejam normalmente surdos aos argumentos mais fortes, enquanto estão sempre inclinados a supervalorizar as exatidões mensuráveis?"

O domínio da mensuração no universo da ciência ainda é defendido como grande critério de rigorosidade e verdade científica por aqueles que defendem a ideia de diferentes formalismos metodológicos. Todavia, mais uma vez Feyerabend (1989:4), completando o argumento de Einstein, dizia que, na atividade científica o grande desafio "não é mais de 'buscar a verdade'... ou a de 'sistematizar observações' ou a de 'aperfeiçoar as previsões'. Esses são apenas efeitos colaterais de uma atividade para a qual sua atenção se dirige diretamente e que é 'tornar forte o argumento fraco"'.

Nessa linha de pensamento, refletir sobre novos desafios metodológicos e epistemológicos para a área da administração significa reconhecer que existe a impossibilidade, perseguida pela maioria de pensadores da área, de se elaborar um ou vários procedimentos metodológicos específicos de trabalho, tendo em vista o fortalecimento da "identidade do campo", que essa postura tem se tornado irrelevante na maioria dos casos, quando não insuficientes. Daí, as 
ideias de um pluralismo metodológico fundamentado e sustentado pela abordagem da complexidade, que por sua vez se sustenta na transdisciplinaridade, que emerge da confrontação das disciplinas, sem procurar o domínio sobre elas, mas a abertura de todas as disciplinas que as atravessa e as ultrapassa se tornam bem-vindas ao universo da administração.

Todavia, essa recepção de novos enfoques não se dá de maneira tranquila e fácil. A defesa de um pluralismo metodológico exige uma postura transgressora por parte dos pesquisadores. Essa transgressão metodológica encontra respaldo no argumento de Feyerabend, que afirma que não existe nenhum cânone de metodologia científica que não tenha sido de alguma maneira violado e transgredido no campo da história da ciência, e completa seu argumento dizendo que grandes cientistas somente alcançaram sucesso por terem quebrado deliberadamente regras sólidas de procedimentos metodológicos (Feyerabend, 1989).

Morin (2005:51) fala que 'transdisciplinar significa hoje indisciplinar. Toda uma enorme instituição burocratizada - a ciência —, todo um corpo de princípios resiste ao mínimo questionamento, rejeita com violência e despreza como 'não científico' tudo o que não corresponde ao modelo.

\section{A abordagem da complexidade e os caminhos da pluralidade}

Toda época gera uma visão geral do mundo, nos dizeres de Kuhn (2006) estabelece um paradigma, ou matriz disciplinar, pelo qual se interpreta e constrói a realidade. A visão de mundo dominante foi completamente condicionada, após três séculos, pelo pensamento cartesiano e a ciência newtoniana. Essa visão nos levou a considerar o mundo um vasto mecanismo de relógio, finito e previsível, independente do homem, dos seus desejos e sonhos. Segundo Morin (2005:12)

tal conhecimento, necessariamente, baseava seu rigor e sua operacionalidade na medida e no cálculo; mas, cada vez mais, a matematização e a formalização desintegram os seres e os entes para só considerar como únicas realidades as fórmulas e equações que governam as entidades quantificadas

Essa representação estática da realidade impossibilitou a percepção da complexidade, da desordem e do caos. Todavia, com o avanço da ciência e o surgimento de novas ferramentas conceituais, tornou-se possível a imersão no mundo inesperado da complexidade. Morin busca demonstrar a necessidade e 
a urgência de um novo modo de pensar a ciência e um modo de pensar sobre o saber humano.

Morin e Le Moingne (2000:62) ao fazerem um balanço do que foi a evolução do pensamento científico apresentam dois níveis de posturas epistemológicas. Há o nível das descobertas empíricas indutivistas "que graças às verificações obtidas por observações e experimentações múltiplas, esclarecia dados objetivos e, sobre esses dados objetivos, induziria a teorias que, pensava-se 'refletiam' o real".

Outro nível seria a formulação de teorias que se fundamentariam na coerência lógica e consequentemente num sistema de ideias. "Haveria, portanto, dois tronos: o trono da realidade empírica e o trono da verdade lógica, de onde se controlava o conhecimento" (Morin e Le Moingne, 2000:62).

$\mathrm{Na}$ sua resposta crítica a esse domínio exercido pelo conhecimento científico tradicional e da pretensão existente de que essas abordagens são os únicos meios adequados para o alcance da verdade científica, Morin e Le Moingne (2000:62) afirmam de maneira categórica que "os princípios da epistemologia complexa são complexos: não existe um trono, não existem dois tronos; não existe absolutamente nenhum trono. Existem instâncias que permitem controlar o conhecimento; cada uma delas é necessária e cada uma delas é insuficiente".

Morin (2005) entende complexidade como um conjunto de acontecimentos, ações, interações, retroações, determinações e acasos, que constituem o nosso mundo. Uma realidade com traços de desordem, de ambiguidades e incertezas, que propõe três princípios que se integram e que resumem em quais fundamentos a abordagem da complexidade se sustenta.

O primeiro princípio é o dialógico, que possibilita a dualidade mantendo a unidade. Tal princípio zela por uma associação, união de lógicas diferentes ou complementares. Exemplo: a ordem e a desordem geralmente estão presentes para melhor interpretar a realidade. A ordem é regularidade, repetição, constância, invariância, previsibilidade. A desordem é irregularidade, novidade, divergência por meio da relação a uma dada estrutura, acaso, imprevisibilidade. A ordem absoluta, onde tudo é determinado, regulado, não permite nenhuma novidade. Não há mais evolução possível. A ordem absoluta elimina a vida. A desordem absoluta não permite mais nenhuma vida. Tudo é fugaz, enganoso. Na realidade, a vida se situa na combinação das duas.

O segundo princípio é recurso organizacional que é entendido como "um processo recursivo no qual os produtos e os efeitos são ao mesmo tempo causas e produtores do que o produz" (Morin, 2005:74). 
O terceiro princípio é o hologramático em que a parte está no todo como o todo está na parte. As partes são indicadoras de características do todo e das possíveis influências que poderão exercer sobre ele e contribuem, assim, para a sua compreensão. Quando se conhece o todo é possível tirar dele elementos que ajudam a conhecer as partes.

Contrário às ideias do senso comum, da simplificação e da totalização do pensamento, Morin (2002) define a abordagem da complexidade como o conjunto de princípios de inteligibilidade que, ligados uns aos outros, poderiam determinar as condições de uma visão complexa do universo físico, biológico, antropossocial. Assim, segundo ele, a complexidade afastaria o pesquisador de uma visão totalizante, sem anular o papel da razão nas análises dos fenômenos sociais. Sob essa ótica, encara-se a racionalidade segundo uma característica dinâmica e flexível, diferentemente daquela estabelecida nos moldes tradicionais, partindo do princípio de que dados aparentemente divergentes ou conflitantes não devam ser simplesmente eliminados do processo de análise, e sim incorporados como aspecto determinante de suas características e evolução.

A grande contribuição de Morin foi destruir os tabus da ciência separados em domínios estanques, cruzando as disciplinas e questionamentos a tão encantada "objetividade" científica.

\section{Pluralismo e complexidade na administração}

Como afirma Genelot (2002), no ambiente das organizações, embora as lógicas sejam distintas, elas não podem ser separadas da realidade da qual fazem parte, pois incorreríamos no mesmo erro incutido no pensamento clássico.

Genelot (2002) procura na sua obra demonstrar como a aplicação dos conceitos simplificação, isolamento e lógica cartesiana pode ser prejudicial no processo de gestão empresarial, pois tendem a manter a empresa sempre no mesmo plano, evitando sua evolução e podendo até comprometer sua sobrevivência. A esse modelo o autor dá a denominação disjunção-exclusão.

Considerando esse modelo ainda pertinente, mas limitado para resolver as complexas questões de gestão das organizações, o autor propõe um modelo mais evoluído de gestão, o da distinção-conjunção, que reforça o conceito da complexidade nos processos e mostra como ela pode ser benéfica para as organizações. Assumindo a existência e coexistência de diferentes níveis de lógicas e suas articulações, como forma de se tratar questões administrativas, o autor defende que esse modelo é mais amplo e pode proporcionar soluções mais consistentes e mais enriquecedoras para as organizações. 
Genelot (2002) permite compreender que a gestão de uma organização não pode mais ser baseada em princípios cartesianos, newtonianos e positivistas, bases da ciência clássica, que têm como um de seus principais objetivos a busca da verdade absoluta, pronta e acabada. As organizações são dinâmicas e sofrem influências internas e externas em diversos níveis, provocando mutações constantes; por isso seus modelos de gestão devem ser mais alinhados aos princípios da complexidade.

A complexidade das estruturas socioeconômicas e a consequente complexidade dos mercados em que as organizações interagem, praticamente obrigam as organizações a adotar uma visão mais ampla de suas estruturas e métodos de gerenciamento. Na constante busca de competitividade em mercados cada vez mais globalizados, precisam saber adaptar modelos de gerenciamento que integram valorização do ser humano com uso de tecnologia como forma de alcançar um diferencial competitivo.

O diferencial de uma organização não pode ser determinado por lógicas parciais e isoladas de um contexto mais amplo. Ele será a conjunção de fatores técnicos, mensuráveis com fatores subjetivos e intangíveis, logo, algo mais complexo. O desafio que se coloca é saber conciliar os dois fatores, aparentemente distintos, mas que podem gerar resultados altamente satisfatórios se trabalhados e interpretados com competência.

Esses novos pontos de vista diante dos eventos organizacionais se refletem na área de administração, que passa a desenvolver ferramentas diferenciadas, que visam não mais prever como será o futuro de uma organização, mas delinear diferentes possibilidades a partir das quais os gestores possam elaborar diversas alternativas de ação. Nessa perspectiva, há uma tentativa de se valorizar o fator humano sobre o desempenho das organizações, com o surgimento de abordagens que incluem a variável em suas análises, tais como o empreendedorismo, o estabelecimento de perfis gerenciais, o empowerment $\mathrm{e}$ a participação nos resultados. Nota-se, no entanto, que todas essas iniciativas estão atreladas às metas financeiras das empresas, que são fatores determinantes no processo de avaliação e que impacta a qualidade e os resultados da gestão, enquanto o ser humano torna-se um elemento periférico nesse processo. As novas abordagens em gestão devem buscar, desse modo, a convergência entre racional (metas financeiras, eficiência, produtividade) e o irracional (fator humano), por meio de novas dinâmicas (Morin, 2002).

Assim, a teoria da complexidade também é responsável pela disseminação da importância de promover uma adequada interação entre as diversas partes que compõem um empreendimento, de modo a definir objetivos que atendam às necessidades básicas das partes, potencializem seus esforços e 
levem a um melhor atingimento das metas propostas. O debate sobre as interações e interferências das partes com o todo, especificamente no âmbito gerencial, é promovida por Genelot (2002), que defende que as organizações são compostas de metassistemas que englobam sistemas de níveis inferiores, ao mesmo tempo em que o controlam e lhe atribuem sentido. É interessante notar que a noção de tempo se diferencia nos quatro metassistemas das organizações, partindo de um primeiro nível, responsável pelas decisões em tempo real; passando por um segundo nível, que se volta às ações de curto prazo; indo para um terceiro nível, que vislumbra questões de médio e longo prazos, mas já passíveis de apresentar suas primeiras evidências; até alcançar um quarto nível, no qual se estabelece uma estrutura mental voltada ao longo prazo, às mutações e quebras de conceitos e teorias. As diferentes noções de prazos fazem com que cada metassistema funcione sob uma lógica própria e diferenciada.

O entendimento da heterogeneidade presente na estrutura interna das organizações, na qual estão inseridos componentes que atuam segundo diferentes modelos mentais, culmina em discussões sobre como as lógicas divergentes acabam influenciando no modo como os gestores interpretam a realidade do mercado em que a empresa atua. Essa constatação impacta diretamente a forma como são estabelecidas as estratégias organizacionais, trazendo a necessidade de ferramentas inovadoras.

A dinâmica da sociedade moderna traz a necessidade de que as diversas áreas do conhecimento adotem uma abordagem cada vez mais aberta, plural e flexível, efetuando relações entre diferentes lógicas de análise. Diante das diversas evidências nesse sentido, torna-se interessante notar o elevado número de teóricos em administração que ainda adotam uma abordagem instrumental positivista como base para a formulação de estratégias engessadas, bem como a tendência à quantificação das atividades empresariais, amplamente visíveis nas mais diversas esferas das organizações e com presença marcante na academia.

Mesmo após ter havido, por teóricos e estudiosos, um reconhecimento das limitações do pensamento racional, determinista e matematizado, promover uma ruptura com esses conceitos parece ainda ser um desafio para área de administração. Esse é um caminho difícil de percorrer, pois significa abrir mão de juízos e prejuízos enraizados e sedimentados nos referenciais teóricos tradicionais.

Vale destacar aqui a afinidade da idéia de "conversa" do pensamento de Morgan, com princípio do diálogo expresso por Morin. Morgan (1983) estabelece como objetivo da pesquisa para os estudos organizacionais, diálogos e 
conversações. Fundamentos que se encontram no livro Beyond method, e que justificam uma estratégia de pesquisa na exploração da conversação como meio de se alcançar a interação social e compreender as estratégias como diferentes vozes em uma conversação sobre a natureza e o status do conhecimento.

A proposta de Morgan tem afinidade com o pensamento de Popper quanto aos objetivos da ciência, que é o de produzir verdades ou declarações provisórias e não conhecimentos objetivos e cabais. Além da afirmação de procedimentos plurais e reflexivos, Morgan (1983:374-375) coloca ênfase na importância da reflexão crítica como base para a ação. Morgan (1983) ao transgredir os ditames normativos da área e fazer uma proposta que vai "além do método" e ao invés de estabelecer cânones de procedimentos, aponta a necessidade de se enxergar o estudo das organizações como conversações.

Sem dúvida, a estratégia de pesquisa proposta por Morgan, já formulada há mais de duas décadas, mesmo não tendo grande impacto na área e entre os pesquisadores, permite um procedimento plural sobre os aspectos metodológicos, além de se sustentar na transdisciplinaridade das "diferentes vozes", possibilitando o desenvolvimento da criatividade e a produção de um conhecimento humano e comprometido com a sociedade.

\section{Considerações finais}

Os estudos na área da administração e das ciências sociais em geral sempre privilegiaram as dimensões de equilíbrio, determinismo e da causalidade simétrica e linear. Dimensões que são particularidades apenas de aspectos e limites de uma realidade. Mas o mundo das organizações e da sociedade em geral apresenta níveis elevados de complexidade, oscilações, instabilidades, auto-organização e profundas mudanças. Assim, o movimento transdisciplinar se afirma de maneira progressiva, como uma crítica aos artificialismos disciplinares construídos a partir do século XIX e fortalecidos no século XX, no domínio de todas as grandes áreas do pensamento, como entre as disciplinas de cada domínio, produzindo toda sorte de ilusicionismo e limite, muito mais por razões institucionais do que epistemológicas. Os desafios trazidos pela compreensão de novos objetos em diferentes áreas encaminham a formação de novas emergências disciplinares, que se manifestam nos novos discursos transdisciplinares.

Nesses novos discursos, é necessário ainda salientar a necessidade de superar, ou mesmo relativizar o domínio do pensamento organizado e estru- 
turado de acordo com os princípios lógico-formais. Isso porque o formalismo não tem resposta para as questões fundamentais colocadas pela sociedade nos tempos atuais e pouco tem a dizer sobre as características evidentes dos seres vivos, como seu cheiro, seu tato, suas paixões e seus amores e desamores. Dimensões humanas que não são passíveis de medição e não estão sujeitas a fundamentos exatos e precisos.

Nos dias atuais, não se pode pensar os fenômenos e os objetos da administração no âmbito das ciências sociais e que não seja de uma forma transdisciplinar e plural. Essa postura permite à área da administração superar os limites entre especialidades hierarquizadas e fechadas e estabelecer caminhos de análise e interpretação comprometida com práticas sociais relevantes para a sociedade. São caminhos que só podem ser construídos por meio de posturas plurais, quer seja do ponto de vista das teorias, dos métodos e das técnicas, sem uma preocupação em formar cânones de regras e procedimentos para a busca da verdade, mas entendendo que a construção do pensamento se dá por vias sinuosas e cheias de percalços, que permite combinar aspectos qualitativos e quantitativos em busca de uma verdade sempre provisória (Popper, 1989), sempre precária e incerta. Afinal, como diz Prigogine (1996), vivemos o tempo do fim das certezas. Portanto, nenhuma área do conhecimento pode ter a pretensão do alcance da verdade final e do saber definitivo.

A reflexão em torno do pluralismo metodológico e da transdisciplinaridade foi enfocada neste artigo com o intuito de reforçar a legitimação de procedimentos e fundamentos teóricos da complexidade, que nos leva a não aceitar, de maneira contemplativa, a realidade social tal como ela é, mas, como afirma Castoriades (1991:71) "não estamos no mundo para olhá-lo ou para suportá-lo, nosso destino não é o da servidão, há uma ação que pode apoiar-se sobre o que existe para fazer existir o que queremos ser".

\section{Referências bibliográficas}

BOURDIEU, P. Sobre a televisão. Rio de Janeiro: Zahar, 1997.

BRYMAN, A. Research methods and organization studies. 2. ed. London: Routledge, 1992.

BURREL, G. Ciência normal, paradigmas, metáforas, discursos e genealogia da análise. In: CLEGG, S. R.; HARDY, C.; NORD, W. R. (Orgs.). Handbook de estudos 
organizacionais. Modelos de análise e novas questões em estudos organizacionais. São Paulo: Atlas, 1999. v. 1, p. 439-462.

CASTORIADES, C. A instituição imaginária da sociedade. 3. ed. Rio de Janeiro: Paz e Terra, 1991.

CHANLAT, T. J. F. Ciências sociais e management: reconciliando o econômico e o social. São Paulo: Atlas, 2000.

CLOSS, L. Q.; ARAMBARURÚ, J. V.; ANTUNES, E. D. Produção científica sobre o ensino em administração: uma avaliação envolvendo o enfoque do paradigma da complexidade. In: ENANPAD, 30., 2006, Salvador. Anais... Salvador, 2006.

EINSTEIN, A. The Born-Einstein Letters. New York: Walter, 1971. p. 192.

FEYERABEND, P. Contra o método. 3. ed. Rio de Janeiro: Francisco Alves, 1989.

. A conquista da abundância: uma história da abstração versus a riqueza do ser. São Leopoldo: Unisinos, 2005.

GENELOT, D. Mananger dans la complexité: réflexions à l'usage dês dirigentes.

3. ed. Paris: Insep, 2002.

KUHN, T. S. O caminho desde a estrutura. São Paulo: Unesp, 2006.

MARIETTO, M. et al. Teoria do caos: uma contribuição para a formação de estratégias. In: ENANPAD, 30., 2006, Salvador. Anais... Salvador, 2006.

MATTOS, P. L. C. L. de. O que diria Popper ao mercado da teoria administrativa? Uma "viagem" da epistemologia à aprendizagem. In: ENANPAD, 25., 2000, Florianópolis. Anais... Florianópolis, 2000.

MEAD, G. H. Mind, self and society. Chicago: University of Chicago Press, 1967.

MORGAN, G. Toward a more reflective social science. In: . (Ed.). Beyond method strategies for social research. London: Sage, 1983a. p. 368-376. . In research, as in conversation, we meet ourselves. In: method strategies for social research. London: Sage, 1983b. p. 405-407. MORIN, E. Ciência com consciência. Rio de Janeiro: Bertrand, 2002. . Introdução ao pensamento complexo. Porto Alegre: Sulina, 2005. ; LE MOINGNE, J. L. A inteligência da complexidade. São Paulo: Peirópolis, 2000.

NIETZSCHE, F. W. A gaia ciência. São Paulo: Hemos, 1976. 
PENA-VEIGA, A.; NASCIMENTO, E. P. do (Orgs.). O pensar complexo: Edgar Morin e a crise da modernidade. 2. ed. Rio de Janeiro: Garamond, 1999.

POPPER, K. A lógica da pesquisa cientifica. 4. ed. São Paulo: Cultrix, 1989. . Conjecturas e refutações. 3. ed. Brasília: UnB, 1994.

PRIGOGINE, I. O fim das certezas: tempo, caos e as leis da natureza. São Paulo: Unesp, 1996.

SANTOS, B. S. Um discurso sobre as ciências. 5. ed. Porto: Afrontamento, 1991. WATSON, J. B. Behaviorism. New York: People's Institute, 1925. 